\title{
Simvastatin Strongly Augments Proapoptotic, Anti-inflammatory and Cytotoxic Activity of Oxicam Derivatives in Doxorubicin-resistant Colon Cancer Cells
}

\author{
KAMILA ŚRODA-POMIANEK ${ }^{1}$, KRYSTYNA MICHALAK ${ }^{1}$, ANNA PALKO-ŁABUZ ${ }^{1}$, \\ ANNA URYGA ${ }^{1}$, BERENIKA SZCZĘŚNIAK-SIĘGA ${ }^{2}$ and OLGA WESOŁOWSKA ${ }^{1}$ \\ ${ }^{1}$ Department of Biophysics, Wroclaw Medical University, Wroclaw, Poland; \\ ${ }^{2}$ Department of Chemistry of Drugs, Wroclaw Medical University, Wroclaw, Poland
}

\begin{abstract}
Background: Incidence of cancer is still increasing. Chemotherapy is often unsuccessful; moreover, anticancer drugs cause serious side-effects. It is necessary to develop effective agents for combination therapies that would increase antitumor effects of treatment and reduce its sideeffects. Materials and Methods: Anticancer activity of oxicam derivatives (PR17 and PR18) alone and in combination with simvastatin on doxorubicin-resistant colon cancer cells was studied. Apoptosis was investigated via caspase-3 activation assay as well as via western blot analysis of expression of apoptotic components, B-cell lymphoma 2 protein (BCL2) and BCL2-associated $X$ protein $(B A X)$. Expression and activity of cyclo-oxygenase-2 (COX2) was also assessed. Results: Oxicam derivatives induced apoptosis through a caspase-3-dependent pathway, up-regulated BAX expression, and down-regulated BCL2 expression. Additionally, oxicam derivatives reduced expression and activity of COX2. Effect of oxicam derivatives on these processes was strongly potentiated by simvastatin. Conclusion: Oxicam derivatives at low concentrations effectively inhibit growth of cancer cells after co-administration with simvastatin.
\end{abstract}

In industrialized countries, the incidence of malignant tumors is still increasing. Chemotherapy is often unsuccessful; moreover, anticancer drugs cause serious side-effects. Cancer cells frequently develop molecular mechanisms responsible for resistance to cytotoxic drugs. Intrinsic or acquired resistance to apoptosis, as well as resistance caused by the overexpression of ATP-binding cassette transporters (ABC

Correspondence to: Kamila Środa-Pomianek, Department of Biophysics, Wroclaw Medical University, ul. Chałubińskiego 10, 50-368 Wrocław, Poland. Tel: +48 717841406, Fax: +48 717840088, e-mail: kamila.sroda-pomianek@umed.wroc.pl

Key Words: Oxicam derivatives, simvastatin, apoptosis, cyclooxygenase- 2 , cancer combination therapy. transporters), are highlighted as being among the most important molecular mechanisms associated with tumor drug resistance (1). Therefore, it is necessary to develop effective agents for combination therapies that would increase antitumor effects of treatment and reduce its side-effects. New data on the antitumor potential of commonly used, nononcological drugs appear regularly in the literature. The challenge is how to recognize active substances in order to identify new classes of molecules devoid of undesirable sideeffects.

In the process of carcinogenesis and chronic inflammation, the overexpression of cyclo-oxygenase-2 (COX2), associated with the increased production of prostaglandin $\mathrm{E}_{2}$, plays a key role (2-5). COX2 is an inducible form of the enzyme that is usually not expressed in normal tissue. Numerous studies have shown that many tumor types (including colon, lung, prostate, and breast cancer) are characterized by significantly elevated prostaglandin $\mathrm{E}_{2}$ level compared to normal tissues (6).

Non-steroidal anti-inflammatory drugs (NSAIDs) demonstrate many desirable mechanisms of action that may add up to a beneficial effect in anticancer therapy. Apart from being COX2 inhibitors, NSAIDs can also induce apoptosis $(7,8)$. Some studies indicated that Caco-2-human colorectal cancer cells exhibited an increased susceptibility to apoptosis after exposure to selective COX2 inhibitors (9). In colorectal cancer cell lines DiFi and DiFi5, NSAIDs in combination with chemotherapy enhanced its efficacy or even circumvented drug resistance (10).

Oxicam derivatives are an important group of NSAIDs, considered multi-target drugs potentially useful in oncology. Oxicams differ from classical NSAIDs (such as salicylates, profenes and phenamates) by the lack of a carboxylic group in their structure. Piroxicam is not only a good antiinflammatory agent but it has also shown chemopreventive activity in different cell lines and animal models [reviewed in (11)]. Modifications of the piroxicam structure have resulted in the introduction to the market of many analogs with more favorable pharmacological profile than the parent 
compound. The limitation in the use of NSAIDs lies in their numerous side-effects, leading to renal, cardiovascular as well as gastrointestinal damage (12).

Statins are cholesterol-lowering drugs widely used in prevention of cardiovascular disease. They are inhibitors of 3-hydroxy-3-methyl-glutaryl-coenzyme A reductase, a key enzyme in cholesterol biosynthesis (13). Because dysregulated lipid metabolism has been recognized as one of the features of cancer cells (14), statins appear to be interesting candidates in cancer treatment $(15,16)$. The pleiotropic anticancer mechanism of statin action by modulation of the expression and activity of proteins involved in the progress of the cell cycle was confirmed in studies performed on leukemia cells (HL-60, MOLT-4) cultured in the presence of these compounds (17). Proapoptotic properties of statins were noted in many cancer cell lines, such as human lymphoblasts and myeloma cells (18), and cell lines derived from colon cancer $(19,20)$ breast cancer (21) and prostate cancer (22).

A promising strategy for increasing the anticancer efficacy of NSAIDs seems to be their use in combination with other drugs with different molecular mechanisms of action such as statins. This may lead to a synergistic effect allowing for a reduction of the dose of each drug required to obtain the desired therapeutic effect. Possible additive effects of statins and NSAIDs in colon cancer chemoprevention has been described by Agarwal et al. (23).

In the present work, the effect of the combined application of oxicam derivatives 4-chlorophenyl-\{2-[3-[4-(2-fluorophenyl)piperazin-1-yl]propyl]-4-hydroxy-1,1-dioxo-1,2benzothiazin-3-yl\}methanone (PR17) and 2-[3-(4-chlorobenzoyl)-4-hydroxy-1,1-dioxo-1,2-benzothiazin-2-yl]-1[4(fluorophenyl)piperazin-1-yl]ethanone (PR18) with simvastatin on resistant cancer cells was studied. PR18 differs from PR17 only in the presence of a carbonyl group. The cytotoxic potential of these oxicam derivatives has been previously noted in our studies on LoVo and LoVo/Dx human colon cancer cells (24). Additionally, PR18 was demonstrated to be an effective resistance modulator in doxorubicin-resistant $\mathrm{LoVo/Dx}$ cells (24). The aim of this work was to investigate whether the co-administration of oxicam derivatives with simvastatin would augment their cytotoxicity, pro-apoptotic, and anti-inflammatory activity.

\section{Materials and Methods}

Chemicals. The structures of simvastatin and oxicam derivatives used in the experiments are presented in Figure 1. PR17 and PR18 were synthesized as previously described (25). Oxicam derivatives and simvastatin (Sigma-Aldrich, Poznan, Poland) were dissolved in dimethyl sulfoxide.

Cell lines. The human colorectal adenocarcinoma cell line LoVo and its doxorubicin-resistant subline $\operatorname{LoVo} / \mathrm{Dx}(26,27)$ were obtained from Institute of Immunology and Experimental Therapy of Polish Academy of Science (Wroclaw, Poland). Cells were grown at $37^{\circ} \mathrm{C}$ in a humidified atmosphere containing $5 \% \mathrm{CO}_{2}$ in Dulbecco's medium supplemented with $10 \%$ fetal bovine serum, L-glutamine and antibiotics. Doxorubicin (Sigma-Aldrich) $(100 \mathrm{ng} / \mathrm{ml})$ was added to the medium to maintain drug resistance of LoVo/Dx cells after each passage which was carried out twice a week. All procedures were carried out in the log-phase of cell growth. The adherent cells were removed from the flask surface using nonenzymatic cell dissociation solution (Sigma-Aldrich). The density of cells for each experiment was determined with EVE Automatic Cell Counter (NanoEnTek, Seoul, Korea).

Cell viability assay. Cell viability was determined using SRB assay (28) with additional modifications. In brief, 60,000 LoVo/Dx cells were seeded in 96 well plates and given a 60 -min attachment period (at $37^{\circ} \mathrm{C}$ ). Thereafter, the cells were treated with different concentrations of the oxicam derivatives alone $(0.1-100 \mu \mathrm{M})$ or in combination with simvastatin $(5 \mu \mathrm{M})$ for $48 \mathrm{~h}$. Control wells contained medium only. The subsequent procedure was carried out as previously described (24). Cytotoxicity of dimethyl sulfoxide to $\mathrm{LoVo} / \mathrm{Dx}$ cells was found to be negligible.

Caspase-3 activation assay. The activity of caspase- 3 was analyzed with the use of a commercially available kit (GenScript, Piscataway, NJ, USA). Cells were seeded $(800,000 /$ well $)$ onto a six-well plate in $2 \mathrm{ml}$ of medium and incubated for $24 \mathrm{~h}$ at $37^{\circ} \mathrm{C}$. The cells were then treated with PR17 or PR18 alone (at $5 \mu \mathrm{M}$ ), and in combination with simvastatin $(5 \mu \mathrm{M})$. After incubation with the studied compounds for $48 \mathrm{~h}$, the cells were scraped and centrifuged $\left(2,000 \times g\right.$ for $5 \mathrm{~min}$ at $\left.25^{\circ} \mathrm{C}\right)$. Spectrophotometric detection $\left(\mathrm{A}_{405}\right)$ of the chromophore p-nitroanilide was used to measure caspase- 3 activity. The relative increase of caspase- 3 activity was determined by calculating the ratio of the absorbance of $p$-nitroanilide in the sample treated with agent to that of the control (with no compound). Camptothecin (Sigma-Aldrich) at 10 $\mu \mathrm{M}$ was used as a positive control.

Western blot analysis. Cells were prepared as described above for caspase-3 activity assay. After $48 \mathrm{~h}$ cells were scraped and centrifuged $\left(2,000 \times g\right.$ for $5 \mathrm{~min}$ at $\left.25^{\circ} \mathrm{C}\right)$. Ice-cold lysis buffer $(1 \%$ Triton X-100, $50 \mathrm{mM}$ Hepes, $150 \mathrm{mM} \mathrm{NaCl}, 1.5 \mathrm{mM} \mathrm{MgCl}_{2}, 1 \mathrm{mM}$ EGTA, $1 \mathrm{mM}$ phenylmethylsulfonyl fluoride, $100 \mathrm{mM} \mathrm{NaF}, 10 \mathrm{mM}$ sodium pyrophosphate, $10 \mu \mathrm{g} / \mathrm{ml}$ aprotinin, and $10 \%$ glycerol, $\mathrm{pH}$ 7.4) was used to lyse cells. After centrifugation $(13,000 \times g$ for $10 \mathrm{~min}$ at $4^{\circ} \mathrm{C}$ ), supernatants were collected for analysis. The protein contents were measured by Bradford method (29). The samples were loaded onto gel for electrophoresis analysis and then transferred onto polyvinylidene difluoride membranes. Incubation with primary antibodies in TBS-T buffer $(0.1 \%$ Triton X-100, $50 \mathrm{mM}$ Tris- $\mathrm{HCl}$, $150 \mathrm{mM} \mathrm{NaCl}, 1, \mathrm{pH} 7.4$ ) containing $5 \%$ bovine serum albumin was performed overnight at $4{ }^{\circ} \mathrm{C}$. The following primary antibodies were used: mouse anti-COX2 (dilution 1:1,000; BD Biosciences, Franklin Lakes, NJ, USA), mouse anti-BCL2 (100/D5, dilution 1:500; Abcam, Cambridge, UK), mouse anti-BAX (2D2, dilution 1:600; Abcam). The level of $\beta$-actin was also determined [mouse monoclonal antibeta actin (C4), diluted 1:5000] as a reference protein. Horse radish peroxidase-linked secondary antibody (dilution 1:1,000; Thermo Scientific, Waltham, MA, USA) was used $\left(30 \mathrm{~min}\right.$ at $\left.4^{\circ} \mathrm{C}\right)$ and after washing with TBS-T, the proteins were visualized. The relative level 


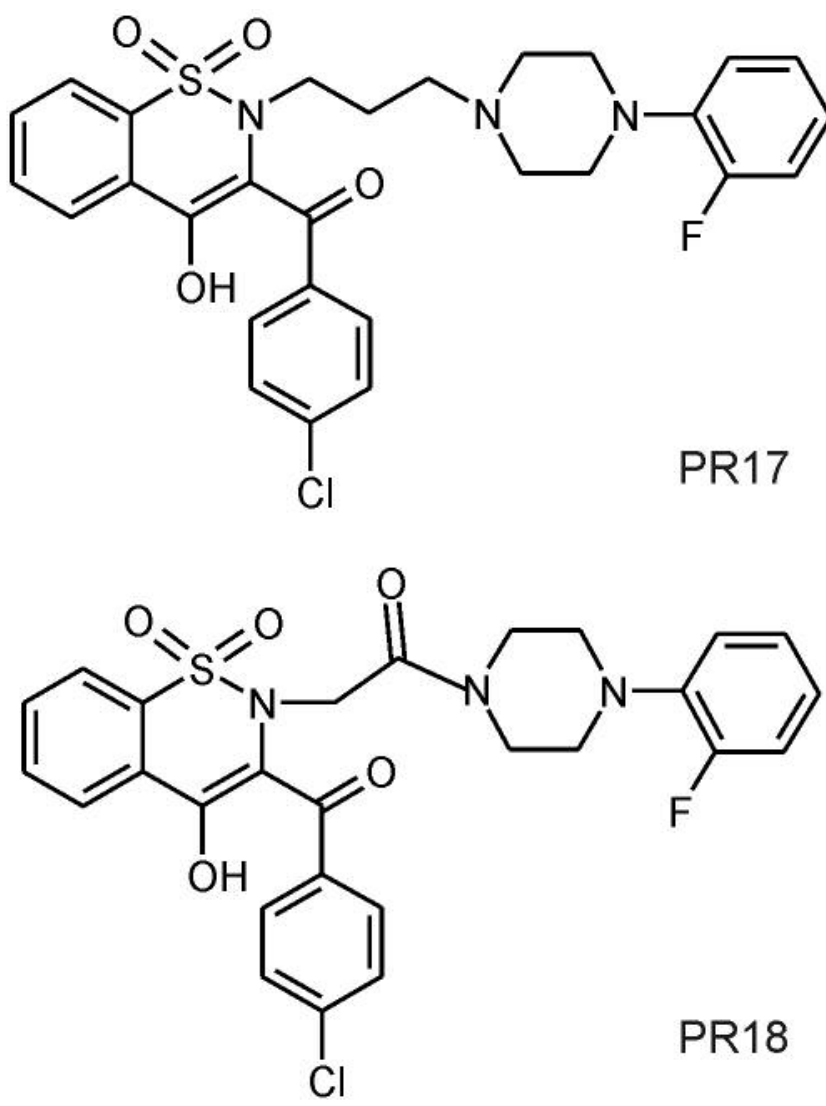<smiles>CCC(C)(C)C(=O)OC1CC(C)C=C2C=CC(C)C(CCC3CC(O)CC(=O)O3)C21</smiles>

Simvastatin

Figure 1. Chemical structure of the modulators used in this study.

of protein normalized to the control derived from non-treated-cells was determined. Image J program (Bethesda, MD, USA) was used to detect the optical density of the bands on the electropherograms. Pan-B-cell lymphoma 2 protein (BCL2) inhibitor ABT-737 (SigmaAldrich) was used at $5 \mu \mathrm{M}$ as a positive control.

COX2 activity assay. Cells were prepared as described above for caspase-3 activity assay. COX2 assay was performed following the recommendations of the manufacturer [Abcam-ab204699 Fluorometric Cyclo-oxygenase (COX) Activity Assay Kit]. After $48 \mathrm{~h}$, cells were harvested, counted $\left(3 \times 10^{6}\right.$ cells for each sample) and washed with phosphate-buffered saline. After centrifugation $(500 \times g$ for $3 \mathrm{~min}$ ), the cell pellet was resuspended in $0.5 \mathrm{ml}$ of lysis buffer with protease inhibitor cocktail. The cell lysate was centrifuged $\left(12,000 \times g\right.$ for $3 \mathrm{~min}$ at $\left.4^{\circ} \mathrm{C}\right)$ and the supernatant was collected. To initiate the reaction, arachidonic acid/ $\mathrm{NaOH}$ solution was added to each sample. Celecoxib (at $2 \mu \mathrm{M}$ ), a specific inhibitor of COX2, was used as a positive control. After addition of arachidonic acid, the fluorescence was recorded $(\mathrm{Ex} / \mathrm{Em}=535 / 587 \mathrm{~nm})$. Activity of COX2 in the test samples was calculated following the recommendations of the manufacturer.

Data analysis. Data represent the mean \pm standard deviation (SD) of at least three replicates. Student's $t$-test was applied and $p$-values of less than 0.05 were considered to achieve statistical significance.

\section{Results}

It was demonstrated previously (24) that oxicam derivatives PR17 and PR18 exerted cytotoxic effect on doxorubicinresistant cancer cells (LoVo/Dx). In the present study, it was checked whether the co-administration of simvastatin would additionally sensitize LoVo/Dx cells to oxicam derivatives. As shown in Figure 2, the combination of oxicam derivatives at different concentrations with simvastatin at $5 \mu \mathrm{M}$ augmented their cytotoxic potential as compared to the control (without simvastatin) $(p<0.05)$. Simvastatin strongly reduced the half-maximal inhibitory concentrations $\left(\mathrm{IC}_{50}\right)$ for PR17 and PR18 against LoVo/Dx cell line. The $\mathrm{IC}_{50}$ for PR17 was 3-fold lower in the presence of simvastatin than in its absence $(100.00 \pm 4.20$ vs. $32.90 \pm 2.60 \mu \mathrm{M}$, respectively). In the case of PR18, simvastatin also reduced its $\mathrm{IC}_{50}$ value by 10 -fold $(2.00 \pm 0.40$ vs. $0.22 \pm 0.01 \mu \mathrm{M})$.

It was also investigated whether cytotoxic activity of oxicam derivatives in LoVo/Dx cells was related to the induction of apoptosis. Thus, the expression of apoptosisassociated proteins, BCL2 and BCL2-associated X protein (BAX) was examined. Western blot analysis revealed that 

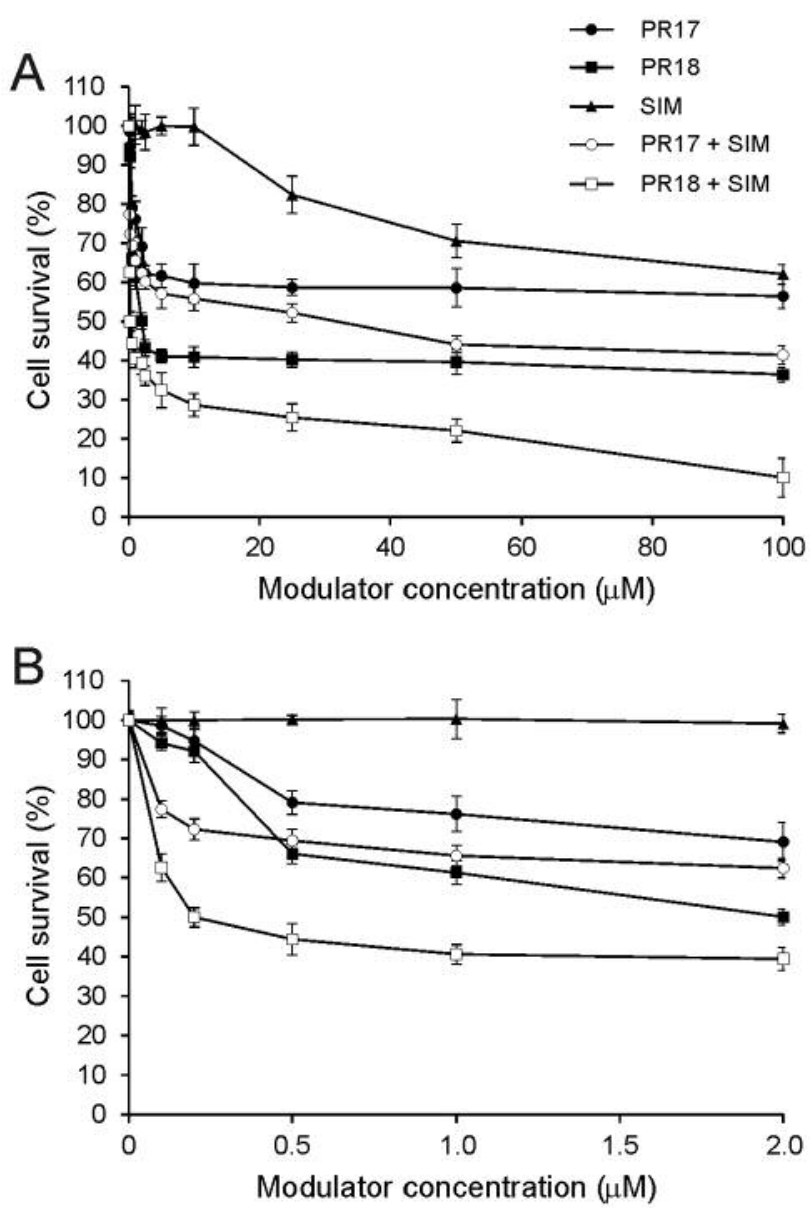

Figure 2. A: Cytotoxicity of PR17, PR18, simvastatin (SIM) and PR17 or PR18 in combination with simvastatin (at $5 \mu M)$ to LoVo/Dx cells. $B$ : The results obtained at low modulator concentrations are presented for the sake of clarity. Means of three experiments $\pm S D$ are presented. The difference in cytotoxicity between PR17 and simvastatin-PR17 combination as well as between $P R 18$ and simvastatin-PR18 combination was statistically significant $(p<0.05)$ for the whole concentration range as determined by the Student's t-test.

PR17 and PR18 (both at $5 \mu \mathrm{M}$ ) induced significant upregulation of pro-apoptotic protein $\mathrm{BAX}$ as compared to the control group $(p<0.05$; Figure $3 \mathrm{~A})$. Under the same conditions, the level of anti-apoptotic BCL2 protein was significantly down-regulated ( $p<0.05$; Figure $3 \mathrm{~A}$ ).

Moreover, simvastatin used at $5 \mu \mathrm{M}$ significantly reduced the BCL2 level and increased BAX level as compared to untreated cells (Figure 3A). When oxicam derivatives were combined with simvastatin (all compounds at $5 \mu \mathrm{M}$ ), augmentation of their influence on the level of apoptosisassociated proteins was noticed (Figure $3 \mathrm{~B}$ and $3 \mathrm{C}$ ), i.e. the level of BCL2 was further diminished whereas that of BAX was further increased.
A

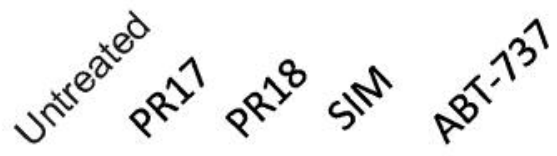

$\mathrm{BCL} 2$

(26 kDa)
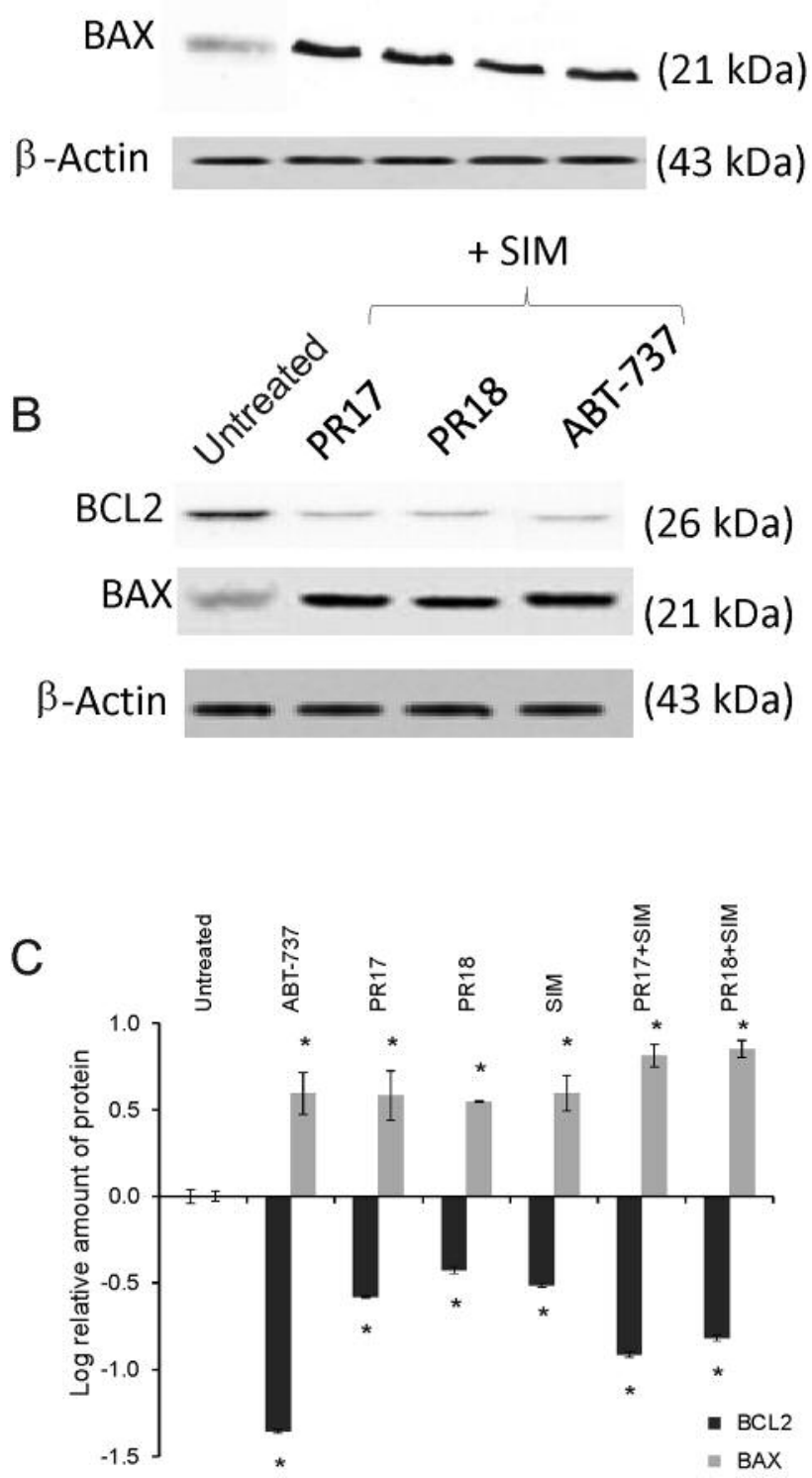

Figure 3. Analysis of B-cell lymphoma 2 protein (BCL2) and BCL2associated $X$ protein $(B A X)$ expression in LoVo/Dx cells cultured for $48 \mathrm{~h}$ with simvastatin (SIM), PR17, and PR18 (all at $5 \mu M$ ) as single agents $(A)$, and with their combinations $(B)$. The molecular masses of proteins are indicated at the right side of the gel. $\beta$-Actin was used as a reference protein. Pan-BCL2 inhibitor ABT-737 was used as a positive control. $C$ : Relative levels of $B C L 2$ and $B A X$ expression normalized to those of the control derived from non-treated LoVo/Dx cells. The results of three experiments $\pm S D$ are presented. *Statistically significantly different from the untreated control at $p<0.05$ (Student's $t$-test). 


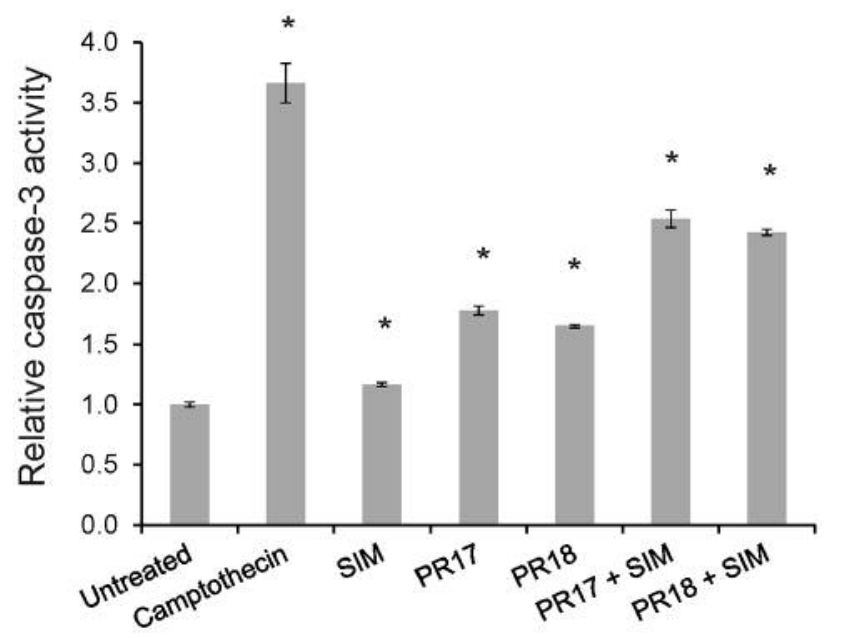

Figure 4. Influence of PR17, PR18, simvastatin (SIM) and their combinations on relative caspase-3 activity in LoVo/Dx cells. Mean values of three experiments $\pm S D$ are presented. Camptothecin was used as a positive control. *Statistically significantly different from the untreated control at $p<0.05$ (Student's t-test).

In a separate experiment the influence of oxicam derivatives on caspase- 3 activity was assayed. Caspase- 3 is critical to many aspects of the apoptotic pathway. Its activation ultimately leads to the execution of apoptosis. As presented in Figure 4, LoVo/Dx cells treated with PR17 or PR18 at $5 \mu \mathrm{M}$ concentration exhibited an increase in the activity of caspase- 3 by over $50 \%$ as compared to the untreated cells. There was no significant difference between the level of caspase-3 activation induced by both oxicam derivatives.

Simvastatin alone (at $5 \mu \mathrm{M}$ ) induced only a subtle increase in caspase-3 activity. On the other hand, its combination with both PR 17 and PR18 resulted in strong increase of caspase3 activity. The enzyme activity was higher by c.a. $50 \%$ in the presence of the simvastatin:oxicam derivative mixture as compared to the activity obtained in the presence of PR17 or PR18 applied alone (Figure 4).

Since oxicam derivatives are used as anti-inflammatory drugs, the influence of PR17 and PR18 on COX2 expression and activity was investigated. High basal expression level of COX2 protein in LoVo/Dx doxorubicin-resistant cell line was observed, being significantly higher than in sensitive LoVo cells (Figure 5A). It was demonstrated that the expression of COX2 protein in LoVo/Dx cells was significantly reduced in the presence of PR17 or PR 18 at $5 \mu \mathrm{M}$ (Figure 5A). The levels of COX2 in the presence of both compounds were comparable and lower than that in untreated cells by more than $80 \%$ (Figure 5A and C).

Simvastatin itself also reduced the expression of COX2 protein when applied at the concentration of $5 \mu \mathrm{M}$ (Figure
A

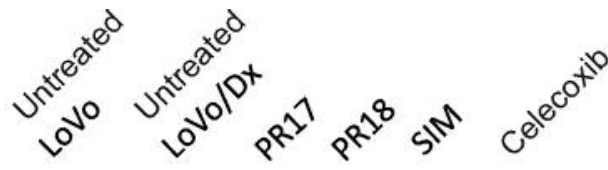

$\operatorname{cox} 2$

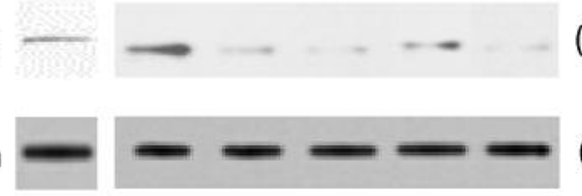

$(75 \mathrm{kDa})$

$\beta$-Actin

$(43 \mathrm{kDa})$

B

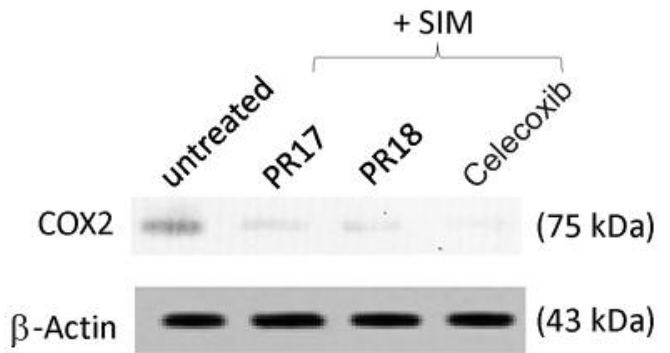

C

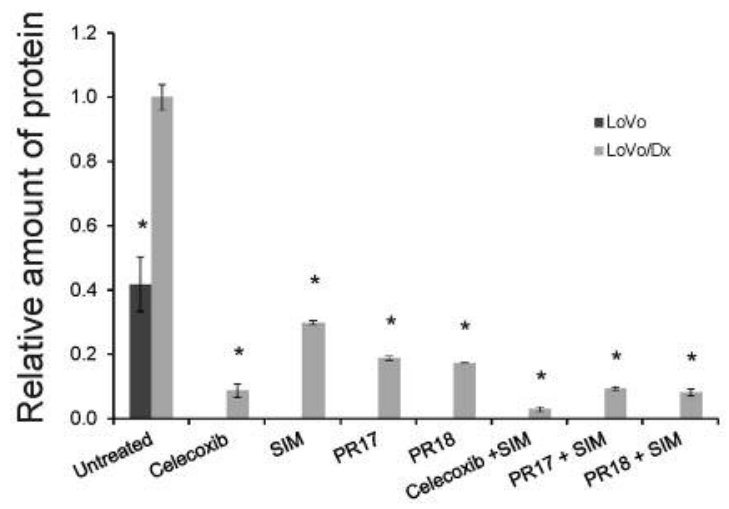

Figure 5. Analysis of cyclo-oxygenase-2 (COX2) protein expression in untreated LoVo cells and in doxorubicin-resistant LoVo/Dx cells cultured with simvastatin (SIM), PR17, and PR18 (all at $5 \mu M$ ) as single agents $(A)$, and with their combinations $(B)$ for $48 \mathrm{~h}$. The molecular masses of the proteins are indicated at the right side of the gel. $\beta$-Actin was used as a reference protein. Celecoxib was used as a positive control. C: Relative level of COX2 expression in LoVo and in LoVo/Dx cells normalized to the control derived from non-treated LoVo/Dx cells. The results of three experiments $\pm S D$ are presented. *Statistically significantly different from the untreated LoVo/Dx control at $p<0.05$ (Student's t-test).

5A). The application of the statin together with PR17 or PR18 further reduced the level of COX2 in LoVo/Dx cells as compared to oxicam derivatives used alone (Figure 5B and C).

The effect of the studied oxicam derivatives (at $5 \mu \mathrm{M}$ ) on enzymatic activity of COX2 was also evaluated (Figure 6). 
COX2 activity was significantly inhibited in LoVo/Dx cells treated with PR17 or PR18. Simvastatin (at $5 \mu \mathrm{M}$ ) exerted qualitatively and quantitatively similar effects as both studied oxicam derivatives. Co-administration of simvastatin with PR17 or PR18 augmented oxicam derivative-induced reduction of COX 2 activity by more than $70 \%$.

\section{Discussion}

In our previous studies, newly-synthesized oxicam derivatives PR17 and PR18 were identified as growth inhibitors of doxorubicin-sensitive and -resistant human colorectal adenocarcinoma cells (LoVo and LoVo/Dx) (24). In this study, it was confirmed that simvastatin co-treatment additionally sensitized resistant cancer cells (LoVo/Dx) to oxicam derivatives. This suggests that simvastatin acted as an effective amplifier of oxicam derivative activity as growth inhibitors in cancer cells. Simultaneous administration of simvastatin and PR 18 resulted in a 10 -fold reduction in the IC50 of PR18 and 3-fold reduction in the case of PR17.

Additionally, it was found that both PR17 and PR18 invoked an apoptotic pathway in LoVo/Dx cells. Both compounds down-regulated the expression of anti-apoptotic BCL2 protein and up-regulated that of pro-apoptotic BAX protein. These proteins are important regulators of apoptosis and therefore constitute important targets for the development of new anticancer agents (1). When the effect of PR17 and PR18 on the expression of BCL2 was studied, it was observed that the addition of simvastatin augmented the effects obtained with oxicam derivatives alone. Additionally, it was found that the up-regulation of BAX by PR17 and PR18 was higher in the presence of simvastatin than in the case of their single application. Similar results were previously obtained for other NSAIDs combined with statins. It was reported that in HCT-116, SW480, and LoVo cell lines, lovastatin was able to augment apoptosis induced by sulindac (23). Celecoxib and fluvastatin, both used as single agents and in combination, reduced the level of expression of anti-apoptotic induced myeloid leukemia cell differentiation protein (MCL1) in hepatocellular carcinoma cells, which resulted in induction of apoptosis and inhibition of cell growth (30).

BCL2 inhibits cell apoptosis by reducing the release of mitochondrial cytochrome $\mathrm{c}$, thus inhibiting the activation of caspase-3 (31). Caspase-3 belongs to the family of cysteine proteases and is a crucial executor of apoptosis (32). In the present work, PR17 and PR18 were demonstrated to significantly elevate caspase-3 activity. Knowing that simvastatin caused about a 2-fold increase of caspase-3 activity in LoVo/Dx cells (20), we have demonstrated additionally that simvastatin enhanced the pro-apoptotic activity of the studied oxicam derivatives in a caspase-3-dependent way. Both simvastatin and NSAIDs were reported to induce apoptosis

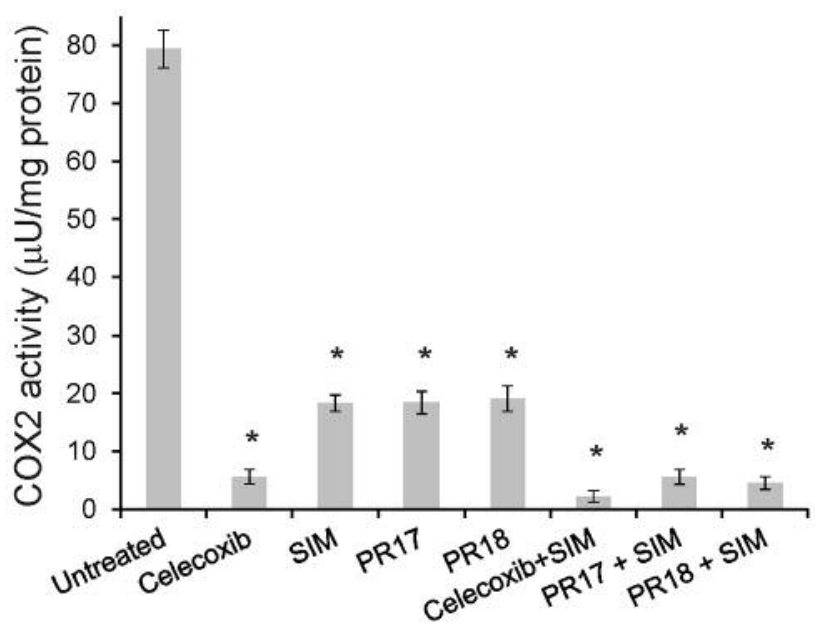

Figure 6. Influence of PR17, PR18, simvastatin (SIM) and their combinations on cyclo-oxygenase-2 (COX2) activity in LoVo/Dx cells. Mean values of three experiments $\pm S D$ are presented. *Statistically significantly different from the untreated control at $p<0.05$ (Student's t-test).

through a caspase-3-dependent mechanism (18). Activation of caspase-3 activity was also previously demonstrated in mesothelioma cell lines treated with piroxicam (33), as well as in HT29 colon cancer cells treated with indomethacin (34). In the same cell line, lovastatin was observed to augment celecoxib-induced activation of caspase-3 (35).

Since chronic inflammation is inevitably associated with carcinogenesis, an elevated level of COX2 expression is observed in cancer cells. In addition, the occurrence of multidrug resistance has been associated with increased expression of COX2 (36-38). Indeed, it was observed here that LoVo/Dx cells exhibited a higher level of COX2 protein expression compared to doxorubicin-sensitive LoVo cells. PR17 and PR18 diminished both the expression and activity of COX2. Simvastatin alone induced a similar reductive effect. Furthermore, a combination of the studied oxicam derivatives with simvastatin produced significantly greater reduction of COX2 level compared to either drug alone. Similar effect of the addition of simvastatin was observed when COX2 enzymatic activity was assessed. Such effects of oxicam derivatives as well as simvastatin on COX2 have been previously reported $(39,40)$. Few reports exist dealing with the influence of combined treatment with statins and NSAIDs on COX2 activity. When rats with induced colon cancer were fed for several weeks with diets containing atorvastatin, sulindac, naproxen or their combinations, the expression of markers of inflammation, such as COX2, was observed to be strongly reduced (41). 
Summarizing, both studied oxicam derivatives affected caspase- 3 activity and regulated the expression of apoptosisrelated proteins BCL2 and BAX in doxorucicin-resistant colon cancer cells. Both compounds also reduced the expression and enzymatic activity of COX2. Moreover, it is worth emphasizing that the effectiveness of these compounds was strongly augmented by their co-administration with simvastatin. These results suggest that oxicam derivatives in combination with simvastatin might effectively inhibit the growth of cancer cells even at low concentrations.

\section{Acknowledgements}

This work was financed by the Polish Ministry of Science and Higher Education (funds for Wroclaw Medical University) and a Research Project for Young Scientists from Wroclaw Medical University (PBmn78).

\section{References}

1 Ramzi MM: Broad targeting of resistance of apoptosis in cancer. Semin Biol 35: S78-S103, 2015.

2 Dimberg J, Samuelsson A, Hugander A and Soderkvist P: Differential expression of cyclo-oxygenase 2 in human colorectal cancer. Gut 45: 730-732, 1999.

3 Chen Q, Shinohara N, Abe T, Watanabe T, Nonomura K and Koyanagi T: Significance of COX2 expression in human renal cell carcinoma cell lines. Int J Cancer 108: 825-832, 2004.

4 Ladetto M, Vallet S, Trojan A, Dell'Aquila M, Monitillo L, Rosato R, Santo L, Drandi D, Bertola A, Falco P, Cavallo F, Ricca I, De Marco F, Mantoan B, Bode-Lesniewska B, Pagliano G, Francese R, Rocci A, Astolfi M, Compagno M, Mariani S Godio L, Marino L, Ruggeri M, Omede P, Palumbo A and Boccadoro $\mathrm{M}$ : Cyclo-oxygenase-2 (COX2) is frequently expressed in multiple myeloma and is an independent predictor of poor outcome. Blood 105: 4784-4791, 2005.

5 Zarghi A and Arfaei S: Selective COX2 inhibitors: A review of their structure-activity relationships. IJPR 10: 655-683, 2011.

6 Dang CT, Shapiro CL and Hudis CA: Potential role of selective COX2 inhibitors in cancer management. Oncology 16: 30-36, 2002.

7 Norouzi M, Norouzi S, Amini M, Amanzadeh A, Irian S and Salimi M: Apoptotic effects of two COX2 inhibitors on breast adenocarcinoma cells through COX2-independent pathway. J Cell Biochem 116: 81-90, 2014.

8 Ding XZ, Tong WG and Adrian TE: Blockade of cyclooxygenase-2 inhibits proliferation and induces apoptosis in human pancreatic cancer cells. Anticancer Res 20: 2625-2631, 2000.

9 Entezari Heravi R, Hadizadeh F, Sankian M, Tavakol Afshari J, Taghdisi SM, Jafarian H and Behravan J: Novel selective COX2 inhibitors induce apoptosis in Caco-2 colorectal carcinoma cell line. Eur J Pharm Sci 44: 479-486, 2011.

$10 \mathrm{Lu} \mathrm{Y}$, Shi C, Qiu S and Fan Z: Identification and validation of COX2 as a co-target for overcoming cetuximab resistance in colorectal cancer cells. Oncotarget 7: 64766-64777, 2016.

11 Earnest DL, Hixson LJ and Alberts DS: Piroxicam and other cyclo-oxygenase inhibitors: potential for cancer chemoprevention. J Cell Biochem Suppl 16I: 156-166, 1992.
12 Ruegg C, Zaric J and Stupp R: Nonsteroidal anti-inflammatory drugs and COX2 inhibitors as anticancer therapeutics: Hypes, hopes and reality. Ann Med 35: 476-487, 2003.

13 Ramkumar S, Raghunath A and Raghunath S: Statin therapy: Review of safety and potential side-effects. Acta Cardiol Sin 32: 631-639, 2016.

14 Mullen PJ, Yu R, Longo J, Archer MC and Penn LZ: The interplay between cell signalling and the mevalonate pathway in cancer. Nat Rev Cancer 16: 718-731, 2016.

15 Van Wyhe RD, Rahal OM and Woodward WA: Effect of statins on breast cancer recurrence and mortality: A review. Breast Cancer 9: 559-565, 2017.

16 Hindler K, Cleeland CS, Rivera E and Collard CD: The role of statins in cancer therapy. Oncologist 11: 306-315, 2006.

17 Martinez-Botas J, Ferruelo AJ, Suarez Y, Fernandez C, GomezCoronado D and Lasuncion MA: Dose-dependent effects of lovastatin on cell-cycle progression. Distinct requirement of cholesterol and non-sterol mevalonate derivatives. Biochim Biophys Acta 1532: 185-194, 2001.

18 Cafforio P, Dammacco F, Gernone A and Silvestris F: Statins activate the mitochondrial pathway of apoptosis in human lymphoblasts and myeloma cells. Carcinogenesis 26: 883-891, 2005.

19 Cho SJ, Kim JS, Kim JM, Lee JY, Jung HC and Song IS: Simvastatin induces apoptosis in human colon cancer cells and in tumor xenografts, and attenuates colitis-associated colon cancer in mice. Int J Cancer 123: 951-957, 2008.

20 Palko-Labuz A, Sroda-Pomianek K, Wesolowska O, KostrzewaSuslow E, Uryga A and Michalak K: MDR reversal and proapoptotic effects of statins and statins combined with flavonoids in colon cancer cells. Biomed Pharmacother 109: 1511-1522, 2019.

21 Aberg M, Wickstrom M and Siegbahn A: Simvastatin induces apoptosis in human breast cancer cells in a NFKB-dependent manner and abolishes the anti-apoptotic signaling of TF/FVIIa and TF/FVIIa/FXa. Thrombosis Res 122: 191-202, 2008.

22 Hoque A, Chen $\mathrm{H}$ and Xu XC: Statin induces apoptosis and cell growth arrest in prostate cancer cells. Cancer Epidemiol Biomarkers Prev 17: 88-94, 2008.

23 Agarwal B, Rao CV, Bhendwal S, Ramey WR, Shirin H, Reddy BS and Holt PR: Lovastatin augments sulindacinduced apoptosis in colon cancer cells and potentiates chemopreventive effects of sulindac. Gastroenterology 117: 838-847, 1999.

24 Sroda-Pomianek K, Wesolowska O, Szczesniak-Siega B, Pula B, Dziegiel P, Maniewska J, Malinka W, Palko-Labuz A and Michalak K: Effect of new oxicam derivatives on efflux pumps overexpressed in a resistant human colorectal adenocarcinoma cell line. Anticancer Res 35: 2835-2840, 2015.

25 Maniewska J, Szczesniak-Siega B, Pola A, Sroda-Pomianek K, Malinka W and Michalak K: The interaction of new piroxicam analogues with lipid bilayers - a calorimetric and fluorescence spectroscopic study. Acta Pol Pharm 71: 1004-1012, 2014.

26 Drewinko B, Romsdahl MM, Yang LY, Ahearn MJ and Trujillo JM: Establishment of a human carcinoembryonic antigenproducing colon adenocarcinoma cell line. Cancer Res 36: 467$475,1976$.

27 Grandi M, Geroni C and Giuliani FC: Isolation and characterization of a human colon adenocarcinoma cell line resistant to doxorubicin. Br J Cancer 54: 515-518, 1986. 
28 Skehan P, Storeng R, Scudiero D, Monks A, McMahon J, Vistica D, Warren JT, Bokesch H, Kenney S and Boyd MR: New colorimetric cytotoxicity assay for anticancer-drug screening. J Natl Cancer Inst 82: 1107-1112, 1990.

29 Bradford MM: A rapid and sensitive method for the quantitation of microgram quantities of protein utilizing the principle of protein-dye binding. Anal Biochem 72: 248-254, 1976.

30 Gao J, Jia WD, Li JS, Wang W, Xu GL, Ma JL, Ge YS, Yu JH, Ren WH, Liu WB and Zhang CH: Combined inhibitory effects of celecoxib and fluvastatin on the growth of human hepatocellular carcinoma xenografts in nude mice. J Int Med Res 38: 1413-1427, 2010.

31 Caroppi P, Sinibaldi F, Fiorucci L and Santucci R: Apoptosis and human diseases: Mitochondrion damage and lethal role of released cytochrome $\mathrm{c}$ as proapoptotic protein. Curr Med Chem 16: 4058-4065, 2009.

32 Lavrik IN, Golks A and Krammer PH: Caspases: Pharmacological manipulation of cell death. J Clin Invest 115: 2665-2672, 2005.

33 Verdina A, Cardillo I, Nebbioso A, Galati R, Menegozzo S, Altucci L, Sacchi A and Baldi A: Molecular analysis of the effects of piroxicam and cisplatin on mesothelioma cells growth and viability. J Transl Med 6: 27, 2008.

34 Kim WH, Yeo M, Kim MS, Chun SB, Shin EC, Park JH and Park IS: Role of caspase-3 in apoptosis of colon cancer cells induced by nonsteroidal anti-inflammatory drugs. Int $\mathrm{J}$ Colorectal Dis 15: 105-111, 2000.

35 Swamy MV, Cooma I, Reddy BS and Rao CV: Lamin B, caspase- 3 activity, and apoptosis induction by a combination of HMG-CoA reductase inhibitor and COX2 inhibitors: A novel approach in developing effective chemopreventive regimens. Int J Oncol 20: 753-759, 2002.

36 Surowiak P, Pawelczyk K, Maciejczyk A, Pudelko M, Kolodziej J, Zabel M, Murawa D, Drag M, Gansukh T, Dietel M and Lage $\mathrm{H}$ : Positive correlation between cyclo-oxygenase 2 and the expression of $\mathrm{ABC}$ transporters in non-small cell lung cancer. Anticancer Res 28: 2967-2974, 2008.
37 Rahman M, Selvarajan K, Hasan MR, Chan AP, Jin C, Kim J, Chan SK, Le ND, Kim YB and Tai IT: Inhibition of COX2 in colon cancer modulates tumor growth and MDR-1 expression to enhance tumor regression in therapy-refractory cancers in vivo. Neoplasia 14: 624-633, 2012.

38 Qiu ZQ and Qiu ZR: Sensitivity of gastric cancer cells to chemotherapy drugs in elderly patients and its correlation with cyclo-oxygenase-2 expression. Asian Pac J Cancer Prev 16: 3447-3450, 2015.

39 Fleischmann R, Iqbal I and Slobodin G: Meloxicam. Expert Opin Pharmacother 3: 1501-1512, 2002.

40 Habib A, Shamseddeen I, Nasrallah MS, Antoun TA, Nemer G, Bertoglio J, Badreddine R and Badr KF: Modulation of COX2 expression by statins in human monocytic cells. FASEB $\mathrm{J} 21$ : 1665-1674, 2007.

41 Suh N, Reddy BS, DeCastro A, Paul S, Lee HJ, Smolarek AK, So JY, Simi B, Wang CX, Janakiram NB, Steele V and Rao CV: Combination of atorvastatin with sulindac or naproxen profoundly inhibits colonic adenocarcinomas by suppressing the p65/ $\beta$-catenin/cyclin D1 signaling pathway in rats. Cancer Prev Res 4: 1895-1902, 2011. 